\title{
Early scrotal approximation after hemiscrotectomy in patients with Fournier's gangrene prevents scrotal reconstruction with skin graft
}

\author{
Oleg Akilov, MD; ${ }^{*}$ Alexandre Pompeo, MD; David Sehrt, BS; ${ }^{+}$Paul Bowlin, MD; ${ }^{+}$Wilson R. Molina, MD; ${ }^{+}$ \\ Fernando J. Kim, $M D^{+}$
}

*Department of Surgery, University of Colorado School of Medicine, Denver, CO; 'Division of Urology, Department of Surgery, Denver Health Medical Center and University of Colorado Health Sciences Center, and the Tony Grampsas Cancer Center, Denver, $\mathrm{CO}$

Cite as: Can Urol Assoc J 2013;7(7-8):e481-5. http://dx.doi.org/10.5489/cuaj.1405 Published online on July 2, 2013.

\section{Abstract}

Objective: We report the outcomes of an early loose closure of the scrotum with a modified $U$-stitch to minimize use of split thickens skin graft for patients with hemiscrotal tissue loss after surgical debridement.

Methods: From January 2006 to August 2011, 28 male patients presented with Fournier's gangrene, requiring major urological surgical care and scrotal debridement at Denver Health Medical Center. Surgical outcomes were compared between patients receiving a novel U-Stitch approximation and those treated by traditional management.

Results: The mean age of the patients was $47.1 \pm 10.2$ years. In total 8 patients $(2.2 \%)$ developed bacteremia and $3(0.1 \%)$ had methicillin-resistant staphylococcus aureus (MRSA) infection. There was conversion from the U-Stitch approximation patients to traditional management. U-stitch patients required less hospitalization than patients requiring split-thickness skin graft (STSG) due to loss of $>50 \%$ of the total scrotal tissue ( 11 vs. 35 days, $p=0.081$ ). The $U$-stitch demonstrated non-inferiority to traditional treatment. Conclusion: Immediate loose scrotal wound approximation with efficient surgical debridement for Fournier's gangrene may prevent testis exposure facilitating local wound treatment, decreasing the length of hospital stay in patients with Fournier's gangrene involving the scrotum. Future randomized trials may validate these findings.

\section{Introduction}

Fournier's gangrene is a type of necrotizing fasciitis (NF) or gangrene usually affecting the perineum and/or external genitalia rapidly spreading to contiguous fascia at a rate up to 1 inch per hour. ${ }^{1}$ It was first described by Baurienne in 1764 but it was named after a French venereologist, JeanAlfred Fournier in $1883 .^{2}$ Infection typically arise when polymicrobial commensal organisms are introduced from the gastrointestinal, genitourinary systems or skin into an immunosuppressed host. Often group A hemolytic streptococcus and Staphylococcus aureus, alone or in synergism initiate infection. Anaerobic bacteria may be present, usually in combination with aerobic gram-negative organisms and proliferate in a hypoxic environment. Due to lower oxidation-reduction potential, gases such as hydrogen, nitrogen, hydrogen sulfide and methane, are produced which may accumulate in soft tissue spaces. ${ }^{3}$ Clinical findings may include swelling, pain, fever, erythema, induration, crepitations, sloughing of the skin, or a blistering and purulent collection. While survival rates improved in the last years due to rapid diagnoses and early therapy, mortality rates are still reported between $16 \%$ to $20 \% .{ }^{4}$ High-risk groups include male patients with diabetes mellitus, malignancy and acquired or induced immunosuppression. ${ }^{5}$ In 1995, Laor and colleagues created the Fournier's Gangrene Severity Index (FGSI) as a way to predict mortality based on the degree of variation from normal in 9 variables. A net score $>9$ is associated with a $75 \%$ mortality rate, and $\leq 9$ had a $78 \%$ survival. ${ }^{6}$ Low hematocrit, low albumin, high blood urea nitrogen (BUN) and creatinine, and elevated alkaline phosphatase were all linked to an increase in mortality among patients with Fournier's gangrene. ${ }^{6}$

The cornerstone of therapy is rapid debridement of necrotized tissue, cardiopulmonary support and broad spectrum antibiotics. ${ }^{5,7}$ Initial choices of antibiotics include third generation cephalosporins, aminoglycosides and metronidazole. ${ }^{7}$ This provides adequate coverage for common infectious agents in Fournier's gangrene, such as Escherichia coli, streptococcus, staphylococcus, enterococcus, pseudomonas, clostridium, klebsiella and bacteroides. Fournier's gangrene is a surgical emergency and a life-threatening condition. The patient must be admitted to an intensive care unit, where broad spectrum antibiotic therapy and immediate and aggressive surgical debridement can be performed. Repeat reassessment for surgical debridement must be performed until the patient is clinically stable, often resulting in important loss of soft tis- 
sue that requires complex reconstructive surgery. Generally, when the scrotum is involved, the testis may be exposed and managed by wet-to-dry dressings until split-thickness skin graft (STSG) may be performed later, or the creation of thigh pouches are needed to protect the testis until final reconstruction is performed. Urinary diversion and diverting colostomy may be needed when perineal/perianal contamination is of concern. Chen et al. proposed an algorithm for management with advancement or transposition flaps according to the area of scrotal defect. ${ }^{8}$ In spite of differences in methodology, all authors agree that scrotal reconstruction is both psychologically and physiologically beneficial to patients. ${ }^{9}$ In the current retrospective study, we evaluated the outcomes of early loose scrotal approximation and possible faster recovery performed by a single surgeon at our institution.

\section{Methods}

A retrospective review was performed on 333 patients with NF at our institution from January 2006 to December 2011. A total of 28 patients were diagnosed with Fournier's gangrene involving the scrotum requiring major urological surgical care. This review study was approved by the institutional review board.

Patients were initially diagnosed in the emergency department with a complete laboratory workup. Preoperative information included demographics, socioeconomic status, comorbidities, body mass index and disease status, including duration of symptoms, demarcation and calculation of the scrotal area involved and laboratory results. Postoperative data included length of hospitalization, necessity of grafts and number of debridement procedures required during hospitalization.

\section{Calculation of scrotal defect}

Scrotal defect was considered as $\leq 50 \%$ (hemiscrotum), or $>50 \%$, depending on whether the debridement crossed the midline raphe (Fig. 1). Scrotal defects after surgical debridement were categorized in 3 groups: Group 1 (Ust), Group 2 (No) and Group 3 (Graft) (Table 1). Of note, U-stitch approximation was initiated after January 2009 while conservative management was standard procedure prior to the

\footnotetext{
Table 1. Categorization of 3 groups

Group 1: $\quad \leq 50 \%$ of scrotal involvement and utilizing the U-stitch Ust approximation

Group 2: $\quad \leq 50 \%$ of scrotal involvement without approximation No and traditional management Group 3: $>50 \%$ of scrotal involvement requiring STSG Graft

UST: U-stitch approximation; No: no approximation; STSG: split-thickness skin graft
}

new approach. The U-stitch was applied to prevent a "piano string" effect and tear the soft tissue.

\section{Treatment}

All patients received standard care, including supportive fluid resuscitation and broad spectrum antibiotic treatment. Antibiotics were adjusted based on culture and sensitivity findings. All patients underwent immediate aggressive debridement, with resection of all necrotic skin, subcutaneous tissue, fascia, and muscle until viable tissue was identified. Patients treated by the conventional technique had the wound packed with gauze; a vacuum-assisted wound closure (VAWC) was applied when needed. ${ }^{10}$ Wound healing was managed by secondary intention or a split thickness skin graft (STSG) when healthy viable tissue and clinical status allowed.

In the study group, loose wound edge closure was performed with a non-absorbable monofilament suture by U-stitch (Fig. 2) approximation of the scrotal and/or perineal wound edges. This simple procedure prevented the testis from being exposed, but allowed a Penrose drain to be placed to permit optimal drainage of the infected area. Postoperatively, additional wet-to-dry dressing changes and irrigation with sterile saline using a Toumey syringe was performed. Urinary diversion or colostomy was applied according to the severity of the infected area. All patients were evaluated often by

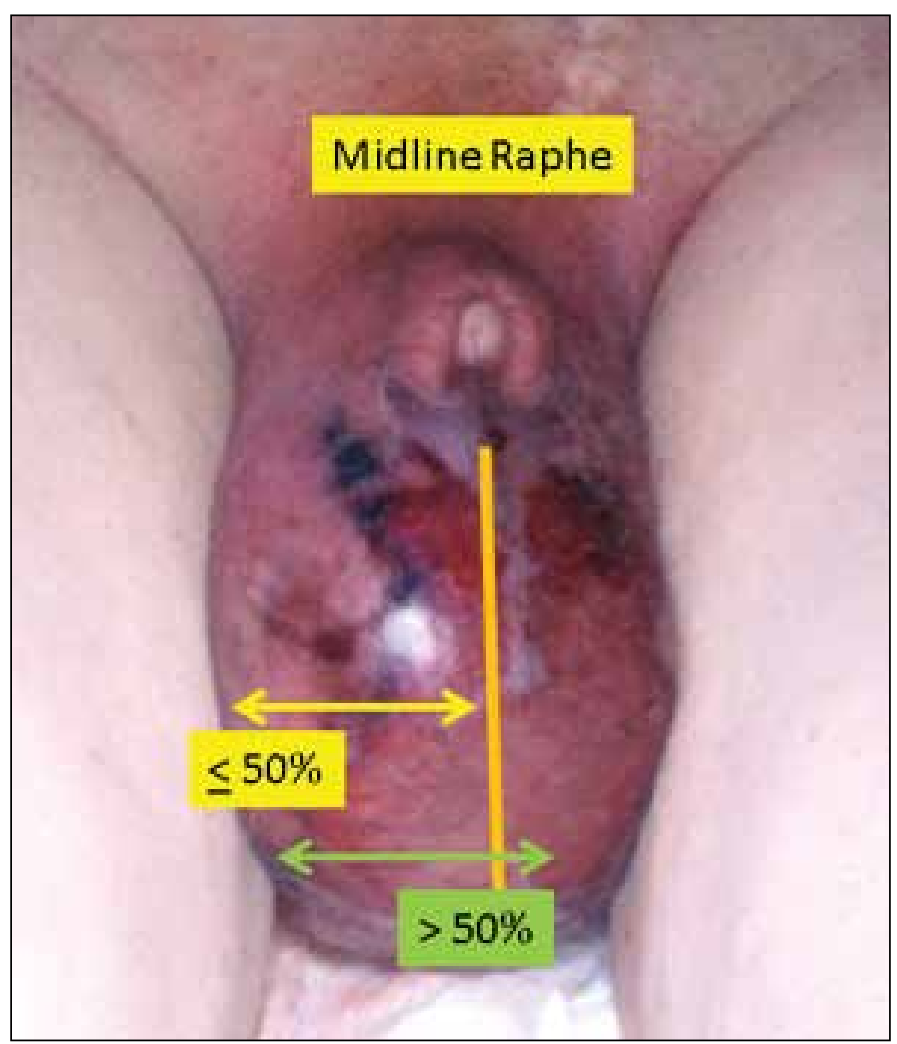

Fig. 1. Calculation of scrotal defect area. 


\begin{tabular}{|c|c|c|c|c|}
\hline & $\begin{array}{c}\text { Group } 1 \\
\text { UST }\end{array}$ & $\begin{array}{c}\text { Group } 2 \\
\text { No }\end{array}$ & $p$ value & $\begin{array}{c}\text { Group } 3 \\
\text { STSG }\end{array}$ \\
\hline Procedures & $6(21 \%)$ & $14(50 \%)$ & & $8(28 \%)$ \\
\hline Age, yr & $46.3 \pm 2.9$ & $46.1 \pm 7.9$ & 0.967 & $48.1 \pm 15.3$ \\
\hline $\mathrm{BMI}, \mathrm{kg} / \mathrm{m}^{2}$ & $28.5 \pm 6.2$ & $35.4 \pm 8.8$ & 0.257 & $28.3 \pm 5.4$ \\
\hline Low income & $5(83.3 \%)$ & $13(92.9 \%)$ & 0.871 & 7 (87.5\%) \\
\hline $\begin{array}{l}\text { Duration of } \\
\text { symptoms } \\
\text { (days) }\end{array}$ & $4.3 \pm 2.0$ & $4.3 \pm 1.5$ & 0.824 & $4.3 \pm 3.8$ \\
\hline $\begin{array}{l}\text { Scrotal } \\
\text { involvement* }\end{array}$ & $50 \%$ & $45 \%$ & 0.133 & $>50 \%$ \\
\hline FGSI & $6.0 \pm 4.5$ & $10.1 \pm 3.9$ & 0.430 & $8.8 \pm 6.2$ \\
\hline \multicolumn{5}{|c|}{$\begin{array}{l}\text { UST: U-stitch approximation; No: no approximation; STSG: split-thickness skin graft; FGSI: } \\
\text { Fournier's Gangrene Severity Index; BMI: body mass index. Co-morbidity: } 14(50 \%) \text { were } \\
\text { diabetic, } 5(18 \%) \text { had renal failure and } 3(10 \%) \text { had malignancies, } 2(7 \%) \text { were HIV positive, } \\
\text { and } 4(14 \%) \text { had hepatitis C and } 2(7 \%) \text { were illicit drug users. } \\
\text { *Percentage compared to total scrotal area refer to Fig. 1. }\end{array}$} \\
\hline
\end{tabular}

the multi-specialty team (general surgery, urology, infectious disease, physical therapy and social services).

Continuous variables were evaluated with the MannWhitney $U$ test. Discrete variables were analyzed with the Chi-squared test. The $p$ values compared groups to the $U$-stich approximation unless otherwise indicated. Data were analyzed using The R Project 2.11 software (The $R$ Project, Wein, Australia). ${ }^{11}$ Statistical significance was determined as $p<0.05$. Data were reported as mean \pm standard deviation and frequency (percentage of the total).

\section{Results}

The mean age of the patients was $47.1 \pm 10.2$ years. Patient demographics, comorbidity and preoperative data were tallied (Table 2). All patients had some comorbidity: 14 (50\%) were diabetic, $5(18 \%)$ had renal failure and $3(10 \%)$ had related pelvic malignancies (colorectal cancer), $2(7 \%)$ were HIV positive, and $4(14 \%)$ had hepatitis C. While tallying the social and economic status of patients, we learned that $3(10 \%)$ patients were homeless and $2(7 \%)$ were illicit drug users. Low income was defined as $<\$ 16450$ for family of $4 .{ }^{12}$

In all 28 patients, the disease started as a poorly defined area of tender hyperemic erythema with progression to healthy tissue. The patients presented to the emergency department between 1 to 6 days after their symptoms started. The scrotum was involved in all patients and occupied on average $50 \%( \pm 27 \%)$ of the total scrotal area. The disease spread to the perineal area in $7 / 28(25 \%)$ patients, inguinal area in $4 / 28(14 \%)$, penis in $1 / 28(0.3 \%)$ and perirectal area in $3 / 28(10 \%)$ patients. The most common combination of antibiotics was vancomycin, piperacillin/tazobactam and clindamycin. The average number of surgical debridement performed in the operating room was 3.5 times. Three of 28 $(10 \%)$ patients had orchiectomy as a result of late epididimoorchitis and $1(0.3 \%)$ patient required ipsilateral orchiectomy due to chronic pain after scrotal STSG reconstruction. The mean length of stay in the hospital was 24.4 days. Eight of 28 (28\%) patients with $>50 \%$ of scrotal defect required STSG, while $6 / 28(21 \%)$ patients had $\leq 50 \%$ scrotal involvement and underwent modified loose $U$-stitch approximation at the same time of debridement. Penrose drains were used to allow wound drainage. No patients underwent hyperbaric oxygen therapy. Group STSG included mostly obese patients, and most Fournier's gangrene patients were low income.

\section{Bacterial isolates in patients with Fournier's gangrene}

Most patients had monobacterial infection (64.3\%). Gram positive cocci (staphylococci, streptococci and enterobacter) were found in 20/28 (71\%) patients (Table 3). Secondary hospital-acquired infection with methicillin-resistant staphylococcus aureus (MRSA) or $P$. aeruginosa complicated the course of the disease in 3/28 (10\%) patients. Beta-hemolytic streptococci was the most common bacteria identified in $11 / 28(39 \%)$ with group A and B seen more commonly in our patients. A total of $8 / 28$ (28\%) had positive blood cultures, which in $3 / 8$ (37\%) had MRSA bacteremia. Prolonged hospital stay was noted in patients with systemic MRSA infection (70 days in patients with MRSA bacteremia versus 5 days for patients who did not have MRSA in their peripheral blood).

Patients who underwent loose scrotal approximation with U-stitch after surgical debridement required less hospitalization than patients who received STSG, but without statistical difference probably due to small number of patients $(p=0.081)$ (Table 3). No patients from Group Ust crossed over to Group Graft.

Although 12 patients achieved a FGSI $>9$, mortality rate within the group of patients studied was $0 \%$. Interestingly, none of the patients had urethral strictures or previous instrumentation of the lower urinary tract.

\section{Discussion}

Fournier's gangrene is an infection with a nidus from colorectal, genitourinary, dermatologic, or unknown ori-

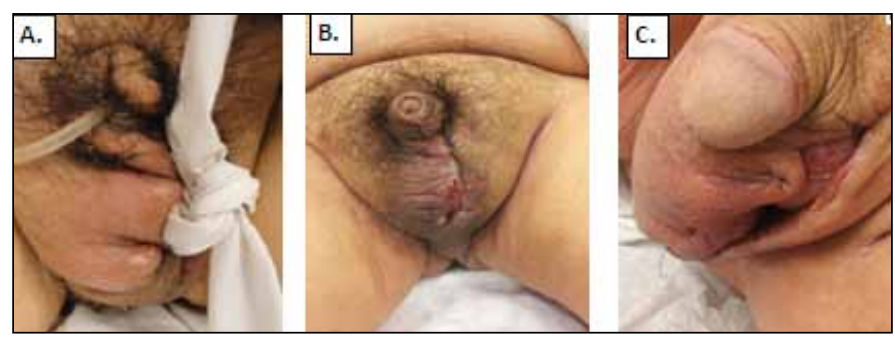

Fig. 2. The U-stich approximation at $(A)$ acute treatment following debridement, (B) after clinical improvement and (C) postoperative healing. 


\begin{tabular}{|c|c|c|c|c|c|}
\hline Microbiology & Group 1 UST & Group 2 No & $p$ value & Group 3 STSG & $p$ value \\
\hline$\beta$-hemolytic Streptococcus & 3 & 5 & - & 3 & - \\
\hline Staphylococcus & 2 & 5 & & 1 & \\
\hline MRSA & 2 & 2 & & 1 & \\
\hline Aerococcus spp. & 0 & 2 & & 1 & \\
\hline Bacteroides & 0 & 1 & & 2 & \\
\hline Enterococcus spp. & 0 & 1 & & 1 & \\
\hline Klebsiella pneumonia & 1 & 0 & & 1 & \\
\hline Pseudomonas aeruginosa & 2 & 0 & & 1 & \\
\hline Candida albicans & 0 & 1 & & 0 & \\
\hline Diphtheroides & 0 & 0 & & 1 & \\
\hline Proteus mirabilis & 0 & 1 & & 0 & \\
\hline Outcomes & G1: Ust & G2: No & $p$ value & G3: STSG & $p$ value \\
\hline No. patients & $6(21.4 \%)$ & $14(50.0 \%)$ & - & $8(28.6 \%)$ & - \\
\hline Debridements & $2.8 \pm 2.6$ & $1.9 \pm 1.0$ & 0.345 & $7.0 \pm 10.1$ & 0.263 \\
\hline Hospitalization & $11.0 \pm 8.2$ & $28.9 \pm 48.1$ & 0.385 & $35.3 \pm 33.0$ & 0.081 \\
\hline STSG & 0 & 0 & - & $8(100.0 \%)$ & 0.001 \\
\hline Colostomy & 0 & $1(7.1 \%)$ & 0.654 & 0 & - \\
\hline
\end{tabular}

UST: U-stitch approximation; No: no approximation; STSG: split-thickness skin graft.

gin. ${ }^{4}$ The infection spreads along the fascial planes of the perineum, scrotum, penis, and can extend to the abdomen, thorax, buttocks and lower extremities in a predictable route.

Involvement of the abdominal wall or lower extremities is associated with increased mortality, and infections with an anorectal origin portend a worse outcome than genitourinary sources. ${ }^{13}$ Although the testicles and spermatic cord are usually spared, as their blood supply is distinct from the skin and fascia of the perineum and scrotum, significant loss of tissue may require future complex reconstructive procedures and temporary thigh pouches for exposed testicles.

We believe that loose approximation of the scrotum is a reasonable option for patients with $<50 \%$ scrotal involvement that can be implemented immediately after debridement without the need of thigh pouches. Several reports have addressed issues with wound care and psychological and physiological aspects of wound care. ${ }^{14}$ In our technique, a Penrose drain prevents premature contraction of the wound and provides egress for residual infection. The appearance of healthy granulation tissue under wet-to-dry dressings in an afebrile patient indicates recovery. Then, the patient is followed as an outpatient with continuation of wet-to-dry dressing at home. On average, a second intention healing process takes between 6 and 9 weeks. The Group No had their wound care as inpatients since most of them had no socioeconomic support for open wound care as outpatients.

Shorter hospital stay occurred for patients managed with the loose wound closure, but was not statistically different probably due to the small number of patients. The total number of debridement was similar between Group Ust and Group No. It appears that the initial debrided area at pre- sentation defined the final extent of tissue loss. Subsequent trips to the operating room resulted in minor debridement.

While surgical debridement and broad-spectrum antibiotics should be administrated as a first-line therapy of this potentially lethal condition, long-term plan for efficient recovery, especially wound care, should be implemented when life-threatening symptoms subside. The importance of surgical debridement upon hospitalization is documented by Sugihara and colleagues. ${ }^{15}$ The case fatality rates were 16.0, $16.9,19.0,26.7$ or $25.0 \%$ among patients who underwent surgery 1, 2, 3, 4 or 5 days after admission, respectively.

Our mortality rate is nil in this study probably due to an aggressive early surgical intervention and a multidisciplinary approach with in house trauma surgeons that deliver surgical care continuously 24 hours a day.

\section{Limitations}

This series has important limitations. The study was retrospective and subject to the inherent biases of the study design. This is also a single institution series with a small number of patients, but Fournier's gangrene has a low incidence rate and large series are difficult to establish.

\section{Conclusion}

Fournier's gangrene is uncommon. Repeat surgical debridement is often necessary, in addition to broad spectrum antibiotic therapy. Diabetes mellitus was often identified as a comorbidity in these patients, as well as other immune-compromising states, including hepatitis $\mathrm{C}, \mathrm{HIV}$ and malnutrition. 
Other risk factors, such as socioeconomic status, alcoholism and illicit IV drug abuse, were identified as risk factors.

Surprisingly, although FGSI was found to be $>9$ in 12 patients, the mortality rate was nil in this study. Early approximation of the scrotal wound at the time of surgical debridement in patients with $\leq 50 \%$ involvement may be safely performed with close monitoring and prevents ipsilateral testis exposure. This surgical approach may expedite recovery, but clinical validation with randomized controls is needed.

Competing interests: None declared.

This paper has been peer-reviewed.

\section{References}

1. Sarani B, Strong M, Pascual J, et al. Necrotizing fasciitis: current concepts and review of the literature. J Am Coll Surg 2009;208:279-88. http://dx.doi.org/10.1016/i.jamcollsurg.2008.10.032

2. Thwaini A, Khan A, Malik A, et al. Fournier's gangrene and its emergency management. Postgrad Med J 2006;82:516-9. http://dx.doi.org/10.1136/pgmi.2005.042069

3. Kihiczak GG, Schwartz RA, Kapila R. Necrotizing fasciitis: a deadly infection. J Eur Acad Dermatol Venereol 2006;20:365-9. http://dx.doi.org/10.1111/i.1468-3083.2006.01487.x
4. Eke N. Fournier's gangrene: a review of 1726 cases. Br J Surg 2000;87:718-28. http://dx.doi.org/10.1046/i.1365-2168.2000.01497.x

5. Erol $B$, Tuncel $A$, Hanci $V$, et al. Fournier's gangrene: overview of prognostic factors and definition of new prognostic parameter. Urology 2010;75:1193-8. http://dx.doi.org/10.1016/j.urology.2009.08.090

6. Vick R, Carson CC 3rd. Fournier's disease. Urol Clin North Am 1999;26:841-9. http://dx.doi.org/10.1016/S0094-0143(05)70224-X

7. Laor E, Palmer LS, Tolia BM, et al. Outcome prediction in patients with Fournier's gangrene. J Urol 1995;154:89-92. http://dx.doi.org/10.1016/50022-5347(01)67236-7

8. Chen SY, Fu JP, Chen TM, et al. Reconstruction of scrotal and perineal defects in Fournier's gangrene. J Plast Reconstr Aesthet Surg 2010;64:528-34. http://dx.doi.org/10.1016/i.bips.2010.07.018

9. McAninch JW. Management of genital skin loss. Urol Clin North Am 1989;16:387-97.

10. Ozturk E, Ozguc H, Yilmazlar T. The use of vacuum assisted closure therapy in the management of Fournier's gangrene. Am J Surg 2009;197:660-5. http://dx.doi.org/10.1016/i.amisurg.2008.04.018

11. Development Core Team. R: A language and environment for statistical computing. R Foundation for Statistical Computing, Vienna, Austria. http://www.r-project.org. Accessed June 12, 2013.

12. Definition of low income. 2011. US Department of Transportation. http://www.fhwa.dot.gov/environment/environmental_justice/training/title_vi/title609.cfm. Accessed June 12, 2013.

13. Kabay S, Yucel M, Yaylak F, et al. The clinical features of Fournier's gangrene and the predictivity of the Fournier's Gangrene Severity Index on the outcomes. Int Urol Nephrol 2008;40:997-1004. http://dx.doi.org/10.1007/s1 1255-008-9401-4

14. Tan BK, Rasheed MZ, Wu WTL. Scrotal reconstruction by testicular apposition and wrap-around skin grafting. J Plast Reconstr Aesthet Surg 2011;64:944-8. http://dx.doi.org/10.1016/i.bips.2010.11.013

15. Sugihara $\mathrm{T}$, Yasunaga $\mathrm{H}$, Horiguchi $\mathrm{H}$, et al. Impact of surgical intervention timing on the case fatality rate for Fournier 's gangrene: an analysis of 379 cases. BJU Int 2012;110:E1096-100. http://dx.doi.org/10.1111/j.1464-410X.2012.11291.x

Correspondence: Dr. Fernando J. Kim, Urological Department, Denver Health Hospital, 777 Bannock St, Denver, C0 80204; fernando.kim@dhha.org 